\title{
Antioxidant and Stabilization Activity of a Quercetin- Containing Flavonoid Extract Obtained from Bulgarian Sophora japonica $\mathbf{L}$.
}

\author{
Dasha Mihaylova $^{1 *}$ and Sebastian Schalow ${ }^{2}$ \\ ${ }^{1}$ Department of Biotechnology; University of Food Technologies; 26 Maritza Blvd.; Plovdiv - 4002; Bulgaria. \\ ${ }^{2}$ Institute of Agricultural and Urban Ecological Projects affiliated to Berlin Humboldt University; Philippstrasse \\ 13; Berlin - 10115; Germany
}

\begin{abstract}
This work aimed to study the antioxidant activity of a quercetin-containing flavonoid extract (QFE) obtained from Sophora japonica L. flower buds rich in quercetin (91.6\%). Radical scavenging activity was analyzed towards the synthetic radicals $\mathrm{DPPH}^{\circ}$ and $\mathrm{ABTS}^{\circ+}$ and antioxidant activity was evaluated applying the method of oxygen consumption in a model system containing methyl linoleate. Model food systems of lard and sunflower oil were explored by the application of Rancimat method and chicken as a real food system was investigated by the thiobarbituric acid test. Results showed a high radical scavenging activity and antioxidant capacity of QFE similar to those of the pure flavonoid quercetin.
\end{abstract}

Key words: Sophora japonica L., antioxidant activity, stabilization activity, Rancimat method

\section{INTRODUCTION}

Due to the carcinogenic potential of synthetic compounds, natural phenolic antioxidants are being targeted as alternatives to minimize, or retard the oxidative deterioration in the food and to improve the health-related functional value of the food (Botsoglou et al. 2002). Many extracts from the herbs, spices, fruits and vegetables are reported to posses a high effectiveness in retarding the rancidity of oils, fats and fatty foods (Shahidi 1997; Madsen et al. 1997; Babovic et al. 2010; Madsen et al. 2000; Espin et al. 2000; Moure et al. 2001; Pokorny et al. 2001; Erkan et al. 2012; Hu and Skibsted 2002). Natural antioxidants (AO) often show equal or even higher antioxidant effects than the synthetic ones. The replacement of synthetic AO with natural AO may have benefits not only for the human health but also for the food systems, since natural AO possess a good solubility in water and/or oil, in different emulsions and food. It is known that dried flowers and buds of Sophora japonica L. are a medicinal herb used in China, Japan and Korea to treat hemorrhoids and hematemesis (Ishida et al. 1989). The main components of $S$. japonica include flavones, tetraglycosides, isoflavones, isoflavone tetraglycosides, triterpene glycosides, phospholipids, alkaloids, amino acids and polysaccharides. S. japonica contains five main flavonoids of rutin, quercetin, isorhamnetin, isorhamnetin, genistein and kaempferol (Kim and Yun-Choi 2008). Its flowers are used as a raw material for different products. Bahchevanska and Koleva (1996) found quercetin and rutin in an extract of $S$. japonica L. blossoms. Moreover,

\footnotetext{
*Author for correspondence: dashamihaylova@yahoo.com
} 
Bahchevanska and Mihaylova (2010) reported that rutin-rich extract was suitable for the stabilization of different lipids, especially those of animal origin.

The aim of the present study was to evaluate the antioxidant effectiveness of natural QFE in various model systems prior to its application in real foods and cosmetics. For this purpose, the extract was studied with different methods for the determination of its radical scavenging activity and its possibility to decrease the lipid oxidation of some food products.

\section{MATERIALS}

\section{Plant material}

The flower buds of $S$. japonica $\mathrm{L}$. were collected in the earlier phase of growth from Plovdiv, Bulgaria, air dried at room temperature $\left(25-28^{\circ} \mathrm{C}\right)$ and then roughly ground and stored in air-tight dark containers until used.

\section{Chemicals}

Trolox (6-Hydroxy-2,5,7,8-tetramethylchroman-2carboxylic acid), DPPH (2,2-diphenil-1picrylhydrazyl radical), dipotassium peroxodisulfate, methyl linoleate and gallic acid were purchased from Aldrich Chemicals (Milwaukee, WI, USA). ABTS (2,2-azino-bis (3ethyl-benzothiazoline-6-sulfonic acid)

diammonium salt, quercetin dihydrate, Tween-20 (polyoxyethlene (20) sorbitan monolaureate) and horse heart metmyoglobin (MMb, type III) were purchased from Sigma (St. Louis, MO, USA). Folin-Ciocalteau reagent, sodium carbonate, BHT (butylated hydroxytoluene) and ethanol (HPLC grade) were supplied from Merck (Darmstadt, Germany). Quercetin, rutin and 1,1,3,3tetraethoxypropane (TEP) were obtained from Sigma-Aldrich Chemie (Steinheim, Germany). Reagents for TBARS analyses, buffer reagents and all other reagents were of analytical grade. Water was purified though a Millipore Q-plus purification train. Lard was rendered extracted in lab scale from the fresh pig fat tissue. Sunflower oil and chicken meat were purchased from the retail shops in Plovdiv.

\section{METHODS}

\section{Preparation of plant extracts}

The quercetin-containing flavonoid extract from $S$. japonica L. was obtained as follows: air-dried and ground flower buds were macerated and extracted three times in $80 \%$ ethanol $(\mathrm{v} / \mathrm{v})$ in a water bath at $70{ }^{\circ} \mathrm{C}$ for $30 \mathrm{~min}$. The solution was then filtered and purified with charcoal $(15 \%$ based on the initial plant mass) for $15 \mathrm{~min}$. The extracts were combined and the solvent was removed by rotary evaporation at $70{ }^{\circ} \mathrm{C}$ to $1 / 3$ of the initial volume. The concentrated solution was diluted with hot water to the initial volume and stored in a refrigerator without any preservatives. The final extract (QFE) was recovered by filtrating the settled residues and drying of the retentate at $60{ }^{\circ} \mathrm{C}$ (Koleva et al. 2005).

\section{Determination of total phenolic content}

The extract was dissolved in $70 \%$ ethanol and analyzed using Folin-Ciocalteu reagent (Amerine et al. 1980). Gallic acid was used as standard for the preparation of a standard curve and the results were expressed as $\mathrm{mg}$ gallic acid equivalents (GAE) per/g crude extract.

\section{HPLC analysis of phenolic compounds in extract}

The extract was dissolved in $70 \%$ ethanol, filtered and $1-10 \mu \mathrm{l}$ of the solution was analyzed by HPLC using a modified method (Rodtjer et al. 2006). Analyses were carried out with a gradient forming Hewlett Packard series 1050 system (Palo Alto, CA, USA), coupled to an Agilent Technologies series 1100 autosampler (Palo Alto, CA, USA). The HPLC system was equipped with a Hichrom Ltd. H1000DS-10C Guard column (Reading, UK) and the separations were performed on a $250 \mathrm{~mm}$ x $4.6 \mathrm{~mm}$ (i.d.) Macherey-Nagel ET Nucleosil ${ }^{\circledR}$ reversed phase $10 \mu \mathrm{m} \mathrm{C}_{18}$ stainless-steel column (Dueren, Germany). The mobile phase consisted of $2.5 \%$ acetic acid in water (solvent $\mathrm{A}$ ), and a mixture of water, methanol and acetic acid (2.5:95:2.5; solvent B). The gradient applied at a flow rate of $1.0 \mathrm{ml} / \mathrm{min}$ was $0-10 \mathrm{~min} 100 \% \mathrm{~A}$ and 10-110 min from 100 to $50 \%$ A. An ESA Analytical Coulochem II dual channel electrochemical detector equipped with an ESA Model 5010 analytical cell (Chelmsford, MA, USA) was used. The settings for the electrochemical detector were channel 1: Potential $0 \mathrm{mV}$; output range $20 \mu \mathrm{A}$, channel 2: Potential $600 \mathrm{mV}$; output range $2 \mu \mathrm{A}$, and the filter time was $2 \mathrm{~s}$ for both the channels. The identification 
and quantification were achieved by comparison with retention times of pure phenolics.

\section{Scavenging of DPPH radicals}

The effect of QFE was evaluated toward the DPPH radical as described by Tadolini et al. (2000) and Schwarz et al. (2001). The ethanol solution of the DPPH $(2.0 \mathrm{ml})$ with a concentration of $40 \mathrm{mg} / \mathrm{ml}(0.1 \mathrm{mM})$ was added to $0.5 \mathrm{ml}$ of an ethanol solution $(70 \%$ ethanol) containing 0.02 $\mathrm{mg} / \mathrm{ml}$ extract, or pure compounds, respectively. Ten minutes after mixing, the absorbance of the solutions was determined spectrophotometrically at $516 \mathrm{~nm}$ using a Cintra 40 UV-visible Spectrometer (GBC Scientific Equipment, Australia). As a blank, $70 \%$ ethanol was used. The inhibition level (\%) of DPPH was calculated using the following equation:

Inhibition level, $\%=\left[\left(\mathrm{Ao}_{-}-\mathrm{A}_{1}\right) / \mathrm{Ao}\right] \times 100$ (1),

where Ao was the absorbance of the control and $\mathrm{A}_{1}$ was the absorbance in the presence of the sample of the tested extracts.

\section{Scavenging of $\mathrm{ABTS}^{\circ+}$ radicals}

The scavenging of $\mathrm{ABTS}^{\circ+}$ was measured according to Re et al. (1999) and Arts et al. (2003). For this, ABTS was dissolved in water to a $7 \mathrm{mM}$ concentration (stock solution) and reacted with $2.45 \mathrm{mM}$ potassium persulfate (final concentration). The mixture was allowed to stand in the dark at room temperature for 12-16 $\mathrm{h}$ before the use. Because ABTS and potassium persulfate reacted stoichiometrically at a ratio of $1: 0.5$, this resulted in incomplete oxidation of the ABTS. The oxidation of the ABTS commenced immediately, but the absorbance was not maximal and stable until more than $6 \mathrm{~h}$ had elapsed. The radical was stable in this form for more than two days when stored in the dark at room temperature. The $\mathrm{ABTS}^{\circ+}$ solution was diluted with ethanol to an absorbance of $0.70 \pm 0.02$ at $734 \mathrm{~nm}$ and equilibrated at $30{ }^{\circ} \mathrm{C}$. After mixing the diluted ABTS $^{\circ+}$ solution $(4.0 \mathrm{ml})$ with a $40 \mu \mathrm{L}$ aliquot of each investigated solution $(0.25 \mathrm{mg} / \mathrm{ml})$, or Trolox in ethanol (final concentration $0-15 \mu \mathrm{M}$ ), the absorbance was measured at $734 \mathrm{~nm}$ after 2 min at $30^{\circ} \mathrm{C}$. Solvent blanks were run in each assay. The inhibition level $(\%)$ of absorbance was calculated using the standard curve prepared with Trolox $(\%$ inhibition level- $\mu \mathrm{M}$ Trolox). The effect of each sample on scavenging $\mathrm{ABTS}^{\circ+}$ was expressed as Trolox equivalent antioxidant capacity (TEAC).

\section{Lipid oxidation assay (Oxygen consumption assay)}

The oxygen consumption is related with the total level of lipid oxidation, and therefore, with the formation of both primary and secondary products of oxidation (Roedig-Penman and Gordon 1998; Hopia and Heinonen 1999). The inhibitory effect of QFE on lipid oxidation in a heterogeneous model system was evaluated by measuring the oxygen consumption in $10 \%$ methyl linoleate in an oil/water emulsion using Tween-20 as an emulsifier. The oxidation was initiated by metmyoglobin $(2 \mu \mathrm{M})$ (Madsen et al. 1997; Madsen et al. 2000; Hu and Skibsted 2002). The relative antioxidative effect of the extract and pure compounds was measured according to $\mathrm{Hu}$ and Skibsted (2002). The influence of each antioxidant on the initial rate of oxygen consumption, $\mathrm{V}\left(\mathrm{O}_{2}\right)$, was calculated as an antioxidative index $\left(\mathrm{I}_{\text {oxy }}\right)$ relative to the rate of oxygen consumption in the absence of the antioxidant:

$\mathrm{I}_{\mathrm{oxy}}=\mathrm{V}\left(\mathrm{O}_{2}\right)$ with extract / V $\left(\mathrm{O}_{2}\right)$ without extract (2)

\section{Antioxidant activity using Rancimat method}

The antioxidant activity of QFE was tested at 100 ${ }^{\circ} \mathrm{C}$ for lard and sunflower oil with the Rancimat method using an apparatus model 697 (Metrohm AG, Herisau, Switzerland) (ISO 6886 1996). The air-flow was fixed at $20 \mathrm{~L} / \mathrm{h}$. QFE was added to the lard and sunflower oil as a solution in absolute ethanol in concentrations of $0.008,0.016,0.032$ and $0.64 \%(\mathrm{w} / \mathrm{w})$. BHT was used as a comparative sample in a concentration of $0.02 \%(\mathrm{w} / \mathrm{w})$. Citric acid was added as a synergist in $0.05 \%$ concentration to the lard and sunflower oil containing $0.016 \%$ QFE. The antioxidant activity, expressed as the protection factor (PF), was calculated by the following equation:

$\mathrm{PF}=\mathrm{IP}$ with extract / IP without extract (3)

\section{Determination of thiobarbituric acid reactive substances (TBARS)}

The activity of QFE toward secondary products of lipid oxidation was evaluated using the thiobarbituric acid test. Chicken meat was minced, homogenized and divided in the portions of $250 \mathrm{~g}$. The extract $(0.01$ and $0.05 \%)$ was added as solution in $70 \%$ ethanol to meat portions (every concentration in duplicate). Reference samples were mixed with $70 \%$ ethanol. The meat portions $(30 \mathrm{~g})$ were vacuum-packed in the bags 
(polyethylene, oxygen rate: $2 \mathrm{~L} / \mathrm{m}^{2} / 24 \mathrm{~h} / \mathrm{atm}$. The bags were heated in a water bath at $100{ }^{\circ} \mathrm{C}$ for 8 min, cooled immediately in ice for $5 \mathrm{~min}$ and stored at $4{ }^{\circ} \mathrm{C}$ for 10 days.

The samples $(5 \mathrm{~g})$ from every meat portion were analyzed for TBARS in duplicate (Vyncke 1970 and 1975). 1,1,3,3-tetraethoxypropane (TEP) was used as a standard for the preparation of a standard curve (Sorensen and Jorgensen 1996). Results were expressed as $\mu \mathrm{M}$ TEP equivalents per $\mathrm{kg}$ of meat.

\section{Statistical analysis}

All the measurements of the different experiments were performed at least in duplicate. The presented data were represented as mean values and statistically analyzed using Microsoft Excel.

\section{RESULTS AND DISCUSSION}

HPLC analysis and total phenol content of QFE The presence of quercetin and rutin in QFE was proved by HPLC analysis. Reverse phase HPLC combined with electrochemical detection showed that the obtained extract mainly consisted of quercetin $(91.6 \%)$ and rutin $(1.4 \%)$. The antioxidant activity of the plant extracts depends on the type and polarity of extraction solvent, the isolation procedure and the nature of the antioxidant components in the raw material. In most cases, the antioxidant properties are related to the presence of phenolic compounds in the extracts (Shahidi and Wanasundara 1992; Jorgenxen 1998; Quiles et al. 2002; Andersen et al. 2003). In the present study, the dry QFE contained high concentrations of phenolics determined as gallic acid equivalents $(425.0 \pm 2.7$ mg GAE/g crude extract). The high concentration of quercetin in QFE is a prerequisite for a high antioxidant activity of the extract.

\section{Scavenging of DPPH ${ }^{*}$ and $\mathrm{ABTS}^{\circ+}$ radicals}

The antioxidant activity of the plant extract is studied with the determination of its radical scavenging activity, as the latter is considered to be the principle mechanism by which the flavonoids are included in retarding the lipid oxidation (Shahidi and Wanasundara 1992; Bettin et al. 2002). For this purpose, experiments with two stable radicals $\mathrm{DPPH}^{\circ}$ and $\mathrm{ABTS}^{\circ+}$ were conducted. Quercetin, as the main component of the extract, was used as a reference standard component. The results are represented as \% inhibition level of DPPH radical (Table 1). QFE showed good scavenging activity on $\mathrm{DPPH}^{\circ}$ similar to the effect of quercetin and trolox used as reference standards. QFE has the ability to act as a free radical inhibitor, particularly with respect to the peroxy radical, which is the propagator of the autoxidation processes in fats and oils.

Table 1 - DPPH radical scavenging activity as \% inhibition level of QFE, quercetin and trolox $(0.02 \mathrm{mg} / \mathrm{ml})$.

\begin{tabular}{lc}
\hline Sample & \% Inhibition level \\
\hline QFE & $62.1 \pm 3.6$ \\
Quercetin & $72.1 \pm 2.4$ \\
Trolox & $74.5 \pm 3.8$ \\
\hline
\end{tabular}

For the establishment of the antioxidant effect of the extract and its electron transfer ability, the method of scavenging the blue-green $\mathrm{ABTS}^{*+}$ radical was applied ( $\operatorname{Re}$ et al. 1999; Arts et al. 2003). The ABTS assay is a method used for the evaluation of the total antioxidant capacity of single compounds and complex mixtures of various plants (Miller et al. 1996). The extent of decolorization of ABTS $^{*+}$ enables the possibility to calculate the antioxidative activity of QFE and quercetin compared to Trolox as the reference antioxidant. The results showed that QFE (10.6 \pm $0.9 \mu \mathrm{M})$ and pure quercetin $(12.5 \pm 0.8 \mu \mathrm{M})$ had similar antioxidant effect toward $\mathrm{ABTS}^{\circ+}$. Higher
TEAC values indicated that the sample had stronger antioxidant activity. From the results it was concluded that QFE could be used as an effective antioxidant for retarding the first step of lipid oxidation and formation of free radicals.

\section{Lipid oxidation}

Since lipid oxidation is a complex multistep process, it is of interest to investigate at which step of lipid oxidation, QFE will influence the process. For this purpose, different methods were used in the present work for the evaluation of its antioxidant activity. QFE was analyzed using the electrochemical method of oxygen consumption, 
which gave more precise information about the ability of the antioxidant to interrupt the chain reaction in propagation of lipid oxidation. This method directly enables the measurement of the rate of oxygen depletion in a model lipid/water emulsion based on methyl linoleate which oxidation is initiated by metmyoglobin. Information about antioxidative effects of the investigated extract and other water-soluble antioxidants was obtained by the values of antioxidative index $\left(\mathrm{I}_{\mathrm{oxy}}\right)$ (Table 2). The $\mathrm{I}_{\mathrm{oxy}}$ of QFE $(0.19 \pm 0.01)$ is comparable to the $\mathrm{I}_{\text {oxy }}$ of pure quercetin $(0.23 \pm 0.01)$ and the effective chain breaking antioxidant Trolox $(0.23 \pm 0.02)-$ the water-soluble equivalent of vitamin $\mathrm{E}$.

Table 2 - Antioxidative index $\left(\mathrm{I}_{\text {oxy }}\right)$ in peroxidizing methyl linoleate oil-in-water emulsions.

\begin{tabular}{ccc}
\hline Product & Concentration, $\mathbf{~ m g} / \mathbf{m l}$ & $\mathbf{I}_{\mathbf{0 x y}}$ \\
\hline QFE & 1.00 & $0.19 \pm 0.01$ \\
Quercetin & 1.00 & $0.23 \pm 0.01$ \\
Trolox & 1.00 & $0.23 \pm 0.02$ \\
\hline
\end{tabular}

\section{Antioxidant activity in model food systems}

A comparative study of the antioxidative action of the derived flavonoid product and BHT as reference was carried out with sunflower oil and lard. Sunflower oil with a peroxide value of 3.7 meq $\mathrm{O}_{2} / \mathrm{kg}$ and fresh obtained lard with peroxide value of $1.2 \mathrm{meq} \mathrm{O}_{2} / \mathrm{kg}$ were used in the present experiments. The results for the induction period (IP, h) and protection factor (PF) are represented in Table 3. The extract exhibited a high antioxidant activity in lard, even higher than BHT which was one of the most used synthetic antioxidant in lipid systems (Buxiang and Fukuhara 1997). The antioxidant activity was improved by increasing the concentration of QFE and the plant extract could be presumed as a good substitute. The activity of the same extract in sunflower oil was negligible $(\mathrm{PF}<2)$. The probable reason for that might be the presence of tocopherols in sunflower oil (Laubli and Bruttel 1986), which were natural antioxidants and preserved the oil itself.

In order to improve the oxidative stability of sunflower oil and lard, the synergistic effect of QFE with citric acid (0.05\%) on the process of lipid oxidation was investigated. The results are shown in Table 4. Particularly in lard, a synergistic effect of the mixture of QFE $(0.016 \%)$ and citric acid $(0.05 \%)$ could be observed which showed in a significant increase in PF (Table 4). In contrast, the increase of $\mathrm{PF}$ in sunflower oil was rather small. Similar synergistic effects were observed by Banaias et al. (1992).

Table 3 - Antioxidant effect (PF) of QFE on lard and sunflower oil at $100{ }^{\circ} \mathrm{C}$ determined by the Rancimat method (ISO 6886).

\begin{tabular}{|c|c|c|c|c|}
\hline \multirow{2}{*}{ Sample } & \multicolumn{2}{|c|}{ Lard $\left(P V=1.2 \mathrm{meq} \mathrm{O}_{2} / \mathrm{kg}\right)$} & \multicolumn{2}{|c|}{ Sunflower oil $\left(P V=3.7 \mathrm{meq} \mathrm{O}_{2} / \mathrm{kg}\right)$} \\
\hline & IP, h & PF & IP, h & PF \\
\hline Control & 6.0 & & 9.1 & \\
\hline BHT, $0.02 \%$ & $13.1 \pm 0.1$ & 2.18 & $11.2 \pm 0.2$ & 1.2 \\
\hline QFE: & & & & \\
\hline $0.008 \%$ & $24.3 \pm 0.5$ & 4.1 & $11.8 \pm 0.3$ & 1.3 \\
\hline $0.016 \%$ & $44.1 \pm 1.1$ & 7.3 & $13.4 \pm 0.5$ & 1.5 \\
\hline $0.032 \%$ & $63.0 \pm 1.2$ & 10.5 & $15.7 \pm 0.3$ & 1.7 \\
\hline $0.064 \%$ & $68.4 \pm 1.1$ & 11.4 & $16.0 \pm 0.2$ & 1.8 \\
\hline
\end{tabular}

Table 4 - Antioxidant effect (PF) of QFE $0.016 \%$ and $0.05 \%$ citric acid (CA) using Rancimat method.

\begin{tabular}{lcc} 
& \multirow{2}{*}{ Product } & \multicolumn{2}{c}{ PF } \\
\cline { 2 - 4 } & Without CA & With CA \\
\hline Lard & 7.4 & 10.1 \\
Sunflower oil & 1.4 & 1.8 \\
\hline
\end{tabular}




\section{Effects of storage on TBARS concentration}

The quantitative evaluation of the antioxidant capacity of the flavonoid compounds in QFE against lipid peroxidation was determined applying the TBARS assay. The antioxidant activity of QFE was tested in a real food system using cooked chicken meat. The extract was added to the meat homogenate in two concentrations $(0.01$ and $0.05 \%)$. Secondary lipid oxidation products such as TBARS were determined in the meat samples treated for $8 \mathrm{~min}$ at $10{ }^{\circ} \mathrm{C}$. The change of TBARS during the meat storage at $4{ }^{\circ} \mathrm{C}$ for 10 days can be seen in Table 5. The TBARS values increased rapidly for the reference sample (without QFE) and after 10 days, the samples of meat homogenates with QFE showed very low values of TBARS compared to the reference, which proved the high activity of the investigated plant extract.

Table 5 - Changes in TBARS ( $\mu \mathrm{M} / \mathrm{kg})$ during storage $\left(4^{\circ} \mathrm{C}, 10\right.$ days) of chicken meat treated with QFE in different concentrations $(0.01$ and $0.05 \%)$ from Sophora japonica.

\begin{tabular}{cccc}
\hline \multirow{2}{*}{ Storage time, days } & \multicolumn{3}{c}{ TBARS, $\boldsymbol{\mu M} / \mathbf{k g}$} \\
\cline { 2 - 4 } & Control & $\mathbf{0 . 0 1 \%} \mathbf{Q F E}$ & $\mathbf{0 . 0 5 \%} \mathbf{Q F E}$ \\
\hline 0 & 0 & 0 & 0 \\
1 & $2.2 \pm 0.01$ & 0 & 0 \\
5 & $4.3 \pm 0.01$ & $0.1 \pm 0.001$ & $0.1 \pm 0.001$ \\
8 & $8.2 \pm 0.03$ & $0.3 \pm 0.001$ & $0.1 \pm 0.001$ \\
10 & $11.0 \pm 0.05$ & $0.5 \pm 0.001$ & $0.1 \pm 0.001$ \\
\end{tabular}

\section{CONCLUSIONS}

The high antioxidant scavenging activity as well as the retarding of lipid oxidation in food systems (lard, sunflower oil and chicken meat) showed the undisputable antioxidant activity of studied flavonoid-rich extract from Sophora japonica L. However, the use of quercetin containing extract in food requires toxicity studies and sensory acceptance. Further research is required to address this concern and validate the beneficial effects and safety of using QFE. The results obtained as well as the information about the toxicity of the synthetic antioxidants used in food products showed the possibility of using the natural extracts such as QFE as alternative sources for antioxidant additives in food processing and generally outline the possibility for their application in food technology.

\section{REFERENCES}

Amerine MA and Ough CS. Total Phenolics- method for analysis of musts and wines. New York: John Wiley; 1980. 181-184.
Andersen ML, Lauridsen RK, Skibsted LH. Optimising the use of phenolic compounds in foods. In: Phytochemical Funktional Foods (Johnson I., Williamson G., eds.). Cambridge: Woodhead Publishing; 2003. 315-346.

Arts MJTJ, Dallinga JS, Voss HP, Haenen GRMM, Bast A. A critical apparaisal of the use of the antioxidant capacity (TEAC) assay in defining optimal antioxidant structure. Food Chem. 2003; 80: 409-414.

Babovic N, Djilas S, Jadranin M, Vajs V, Ivanovic J, Petrovic S, Zizovic I. Supercritical carbon dioxide extraction of antioxidant fractions from selected Lamiaceae herbs and their antioxidant capacity. Innov Food Sci Emerg Technol. 2010; 11: 98-107.

Bahchevanska S and Koleva I. A study on the autohydrolysis of rutin to quercetin from Sophora japonica blossoms. Biotechnol \& Bioechnol. Eq. 1996; 1: 56-58.

Bahchevanska $\mathrm{S}$ and Mihaylova D. Investigation of possibility for stabilization of different natural lipids and oils through the addition of plant extract from Sophora japonica, Journal of International Scientific Publications. 2010; 4 (1): 128-135.

Banaias C, Oreopoulou V, Thomopulus CD. The effect of primary antioxidants and synergists of the activity of plant extracts in lard. JAOCS. 2003; 69: 520-524. 
Bettin SM, Isique WD, Franco DW, Andersen ML, Knudsen S, Skibsted LH. Phenols and metals in sugar-cane spirits. Quantitative analysis and effect on radical formation and radical scavenging. Eur Food Res Technol. 2002; 215: 169-175.

Botsoglou NA, Christaki E, Fletouris DJ, Florou-Paneri $\mathrm{P}$, Spais AB. The effect of dietary oregano essential oil on lipid oxidation in raw and cooked chicken during refrigerated storage. Meat Sci. 2002; 62: 25965.

Buxiang S and Fukuhara M. Effect of coadministration of BHT, BHA and flavonoides an the activation of mutagens and drug-metabolising enzymes in mice. Toxicology. 1997; 122: 61-72.

Erkan N, Ayranci G, Ayranci E. Lipid oxidation inhibiting capacities of blackseed essential oil and rosemary extract. Eur J Lipid Sci Technol. 2012; 114 (2): $175-184$

Espin JC, Soler Rivas C, Wishers HJ, Garcia-Vignera C. Anthocyanin- based natural colorants: A new source of antiradical activity for foodstuff, J Agric Food Chem. 2000; 48: 1588-1592.

Hopia A and Heinonen M. Antioxidant activity of Flavonol Aglycones and Their Glycosides in Methyl Linoleate. JAOCS. 1999; 76 (1): 139-144.

$\mathrm{Hu} \mathrm{M}$ and Skibsted LH. Antioxidative capacity of rhizome knot extract of edible Lotus (Nelumbo nuficera). Food Chem. 2002; 76: 327-333.

Ishida H, Umino T, Tsuji K, Kosuge T. Studies on the antihemostatic substances in herbs classified as hemostatics in traditional Chinese medicine. I. On the antihemostatic principles in Sophora japonica L. Chem Pharm Bull (Tokyo). 1989; 37: 1616-1618.

ISO 6886: Animal and vegetable fats and oilsDetermination of oxidative stability. 1996.

Jorgenxen LV. Flavonoids and other naturally occurring antioxidants. Physico-chemical aspects of their antioxidant mode of action [PhD Thesis]. Denmark: The Royal Veterinary and Agricultural University; 1998.

Kim JM and Yun-Choi HS. Anti-platelet effects of flavonoids and flavonoidglycosides from Sophora japonica. Arch Pharm Res. 2008; 31 (7): 886-890.

Koleva B, Stanchev V, Spasova D, Bahchevanska S. Investigation of the process maceration of flowers from Sophora japonica. Food Science, Engineering and Technologies. Scientific works. Plovdiv: UFT; 2005. 380-385.

Laubli $\mathrm{M}$ and Bruttel P. Determination of oxidative stability of fats and oils, comparison between the active oxygen method and the Rancimat method. JAOCS. 1986; 63: 792-795.
Madsen HL, Andersen CM, Jorgensen LV, Skibsted LH. Radical scavenging by dietary flanonolids. A kinetic study of antioxidant effectiveness. Eur Food Res Technol. 2000; 211: 240-246.

Madsen HL, Bertelsen G, Skibsted LH. Antioxidative activity of spices and spice extracts. In: Risch SJ, HO CT, (eds.) editors. Spices, flavour chemistry and antioxidant properties. ACS Symposium. Series 660. Washington: American Chemical Society; 1997.

Miller NJ, Sampson J, Candeias LP. Antioxidant activities of carotenes and anthophylls. FEBS Letters. 1996; 384: 240-242.

Moure A, Cruz Y, Franco D, Domingues J, Sineiro Y. Natural antioxidants from residual sources. Food Chem. 2001; 72: 145-171.

Pokorny J, Yanishlieva N, Gordon M. (Eds.). Antioxidants in Food: Practical Application. Cambridge: Woodhead Publishing Ltd and CRC Press LLC; 2001.

Quiles JL, Ramirez-Tortosa MC, Gomez JA, Huertas JR, Mataix J. Role of vitamin E and phenolic compounds in the antioxidant capacity, measured by ESR, of virgin olive, olive and sunflower oils after frying. Food Chem. 2002; 76: 461-468.

Re R, Pellegrini N, Proggente A, Pannala A, Yang M, Rice-Evans C. Antioxidant activity an improved ABTS radical cation decolorization assay. Free Rad Biol \& Med. 1999; 26 (9/10): 1231-1237.

Rodtjer A, Skibsted LH, Andersen ML. Antioxidative and prooxidative effects of extractsmade from cherry liqueur pomace. Food Chem. 2006; 99: 6-14.

Roedig- Penman A and Gordon M. Antioxidant Properties of Myricetin and Quercetin in Oil and Emulsions. JAOCS. 1998; 75 (2): 169-180.

Schwarz K, Bertelsen G, Nissen LR, Gardner PT, Heinonen MI, Hopia A, Huynh-Ba T, Lambelet P, McPhail D, Skibsted LH, Tijburg L. Investigation of plant extracts for the protection of processed foods against lipid oxidation. Comparison of antioxidant assays based on radical scavenging, lipid oxidation and analysis of the principal antioxidant compounds. Eur Food Res Technol. 2001; 212: 319-328.

Shahidi F and Wanasundara PKJPD. Phenolic antioxidants. Critical Reviews in Food Science and Nutrition. 1992; 32: 67-103.

Shahidi F. (Ed.). Natural Antioxidants: Chemistry, Health Effects, and Application. Champaign, Illinois: AOCS Press; 1997.

Sorensen G and Jorgensen, SS. A critical examination of some experimental variable in the 2-thiobarbituric Acid (TBA) test for lipid oxidation in meat products. Z Lebensm Unters Forsch, 1996; 202: 202-210. 
Tadolini B, Juliano C, Pui L, Franconi F, Cabrini L. Resveratrol inhibition of lipid peroxidation. Free Rad Res. 2000; 22: 105-114.

Vyncke W. Direct Determination of the Thiobarbituric Acid Value in Trichloracetic Acid Extracts of Fish as a Measure of Oxidative Rancidity. Fette, Seifen, Anstrichm. 1970; 72: 1084-1087.
Vyncke W. Evaluation of Direct Thiobarbituric Acid Extraction Method Oxidative Rancidity in Mackerel (Scomber scombrus L.). Fette, Seifen, Anstrichm. 1975; 77: 239-240.

Received: April 24, 2012; Revised: October 05, 2012; Accepted: May 06, 2013. 